\title{
Response Spectrum Analysis of Response of Building with Setbacks
}

\author{
Ajay Singh Gulshan ${ }^{1}$, Poonam Dhiman ${ }^{2}$ \\ ${ }^{1,2}$ (Department of Civil Engineering, JUIT, waknaghat, India)
}

\begin{abstract}
The past earthquakes have shown catastrophic effect on the buildings with irregularities. It was seen that the buildings with irregularities are more prone to earthquake then the regular building. The structure with irregularities are called irregular structures. Irregularities in a building can be due to the uneven distribution of mass, stiffness and geometry of the structure. In the present paper a special case of vertical irregularity i.e. setback is discussed. Seven types of buildings are taken for analysis, out of which one is regular building and rest are buildings with setbacks at different storey height. All six irregular structures are compared with the regular structure on the basis of shear force, axial force and bending moment at setbacks. It was found that the value of axial force in all beams and columns are increasing drastically as we move from regular to irregular structure. It was interesting to note that, however the mass of the building is reducing but forces at setbacks are increasing to a great extent. The analysis suggest that the setbacks introduced in a building can be proven disastrous at the time of earthquake hence it is not recommended to introduce setbacks in a building.
\end{abstract}

Keywords - plan irregularities, vertical irregularities, setbacks

\section{INTRODUCTION}

In the modern world one can see plenty of manmade marvels, from zifen tower to burj khalifa each one has its own charm. During the design of these types of structure one major parameter that is needed to be analyzed is the response of the building during earthquake. As it is known to all that the earthquake is the most devastating and unpredictable natural disaster. It has been seen in the past earthquakes that the degree of damage done to these kind of buildings is more due to their irregularities. That is why it becomes very important to the designing team of the project to know how the building will behave during earthquake. There are two types of irregularities in a building i.e. plan irregularities and vertical irregularities. This research paper focus on the behavior of the building during earthquake due to a subcase of setbacks at different storey level. IS 1893 (Part 1):2002 have given criteria for setbacks in a building, which are shown in fig1 [1]. If these criteria are met, then the structure is irregular structure otherwise it will be considered as regular structure. In this paper all three types of setbacks are considered for study and are compared with the regular structure.
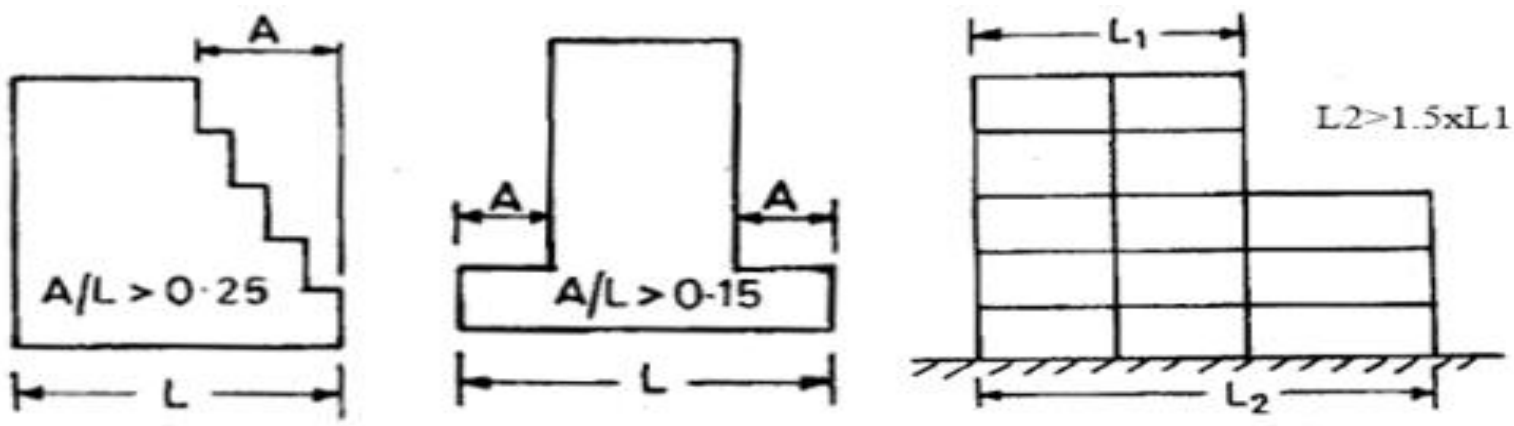

Fig.1 Types of Setbacks 


\section{METHODOLOGY}

Response spectrum analysis of all the frames is done using Staad.Pro V8i and the value of maximum axial force, maximum shear force and maximum bending moment are calculated for the structures with setbacks and compared with the same member in regular structure.

\section{SYSTEM MODEL}

This work is based on seven structure, one regular and six irregular. All the structure shown in fig. 2 have the same height and width i.e. $25.6 \mathrm{~m}$ and $20 \mathrm{~m}$ respectively. Structure 2 have a setback on the sixth storey, structure 3 on five and seven, structure 4 on second, third, five and seven, structure 5 on sixth storey, structure 6 on fourth storey and structure 7 on fourth and seventh storey. Height and width of each storey is $3.2 \mathrm{~m}$ and $5 \mathrm{~m}$ respectively. Dead load of $20 \mathrm{kN} / \mathrm{m}^{2}$, live load of $10 \mathrm{kN} / \mathrm{m}^{2}$ and $5 \mathrm{kN} / \mathrm{m}^{2}$ (on roof) and seismic load

\section{STRUCTURE 1}
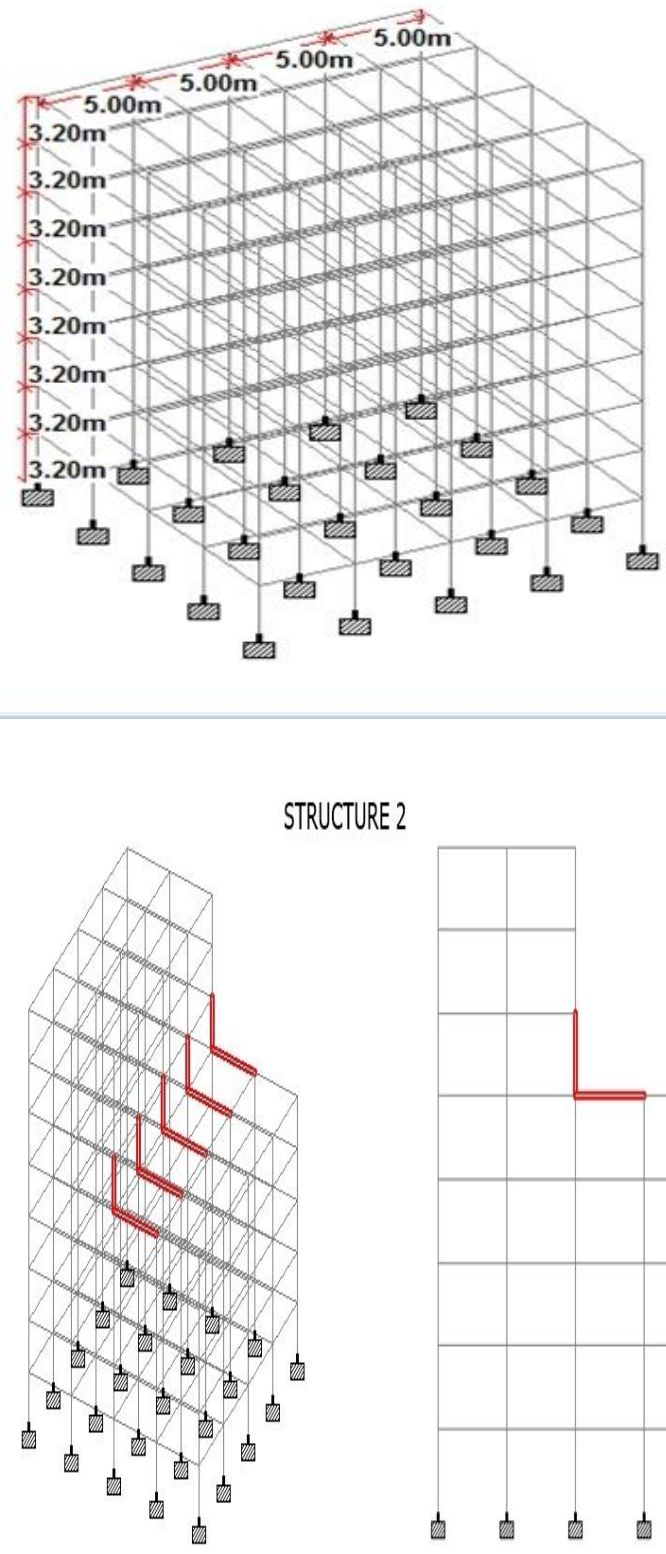

STRUCTURE 2

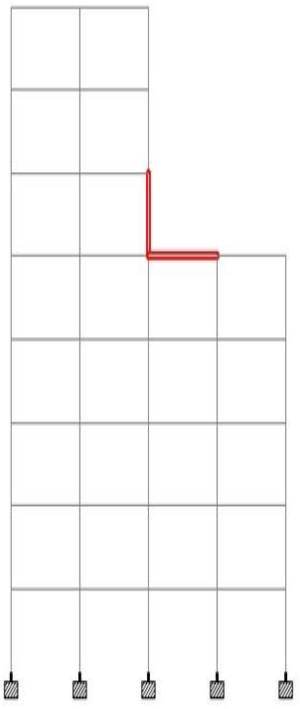

\begin{tabular}{|c|c|c|c|}
\hline $3.20 \mathrm{~m}$ & $5.00 \mathrm{~m}^{1 / 4}$ & $5.00 \mathrm{~m}^{-1 / 4}$ & $5.00 \mathrm{~m}$ \\
\hline $3.20 \mathrm{~m}$ & & & \\
\hline $3.20 \mathrm{~m}$ & & & \\
\hline $3.20 \mathrm{~m}$ & & & \\
\hline $3.20 \mathrm{~m}$ & & & \\
\hline $3.20 \mathrm{~m}$ & & & \\
\hline $3.20 \mathrm{~m}$ & & & \\
\hline $3.20 \mathrm{~m}$ & $\mathbb{Z}$ & $E$ & $\theta$ \\
\hline
\end{tabular}

STRUCTURE 3
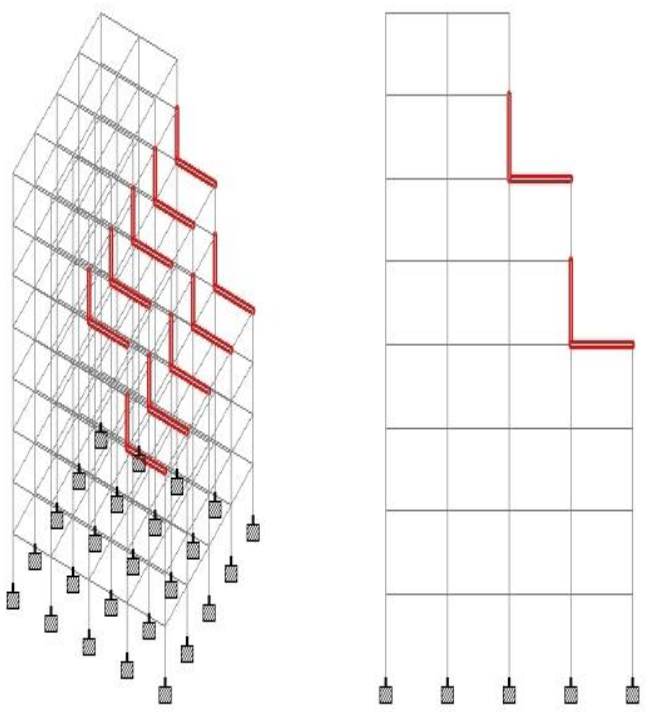


\section{STRUCTURE 4}
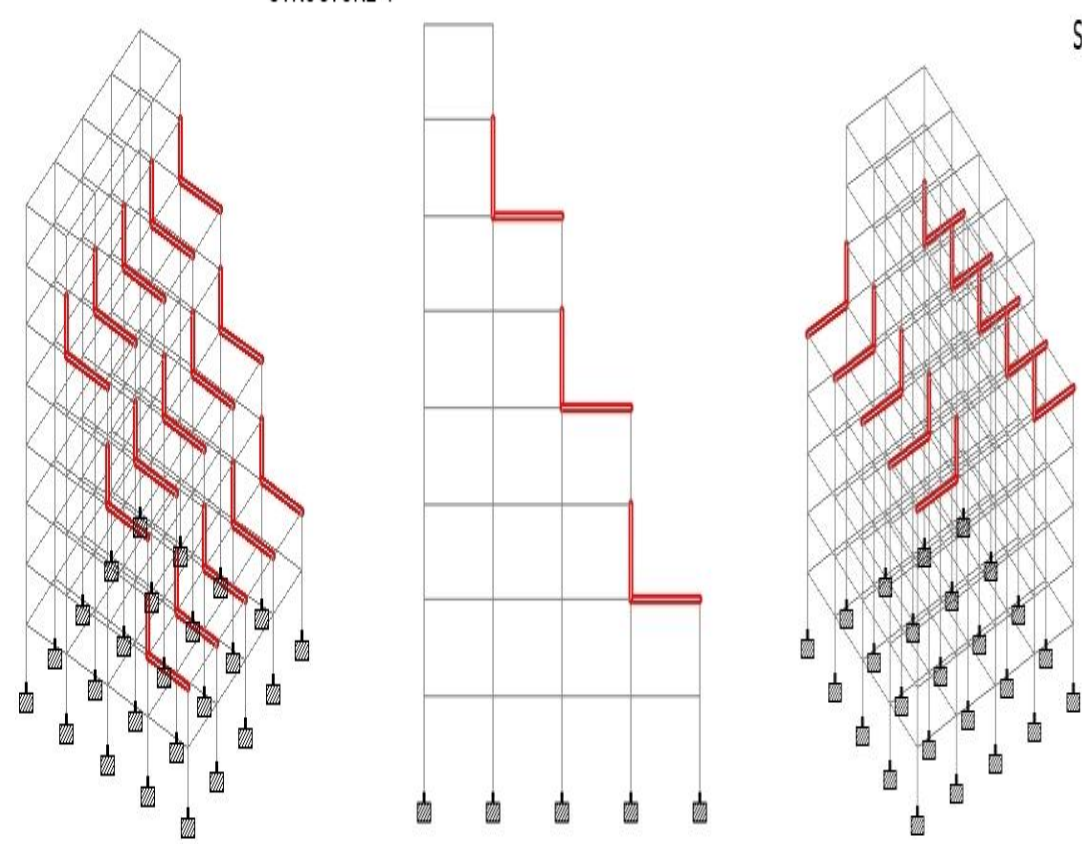

STRUCTURE 5
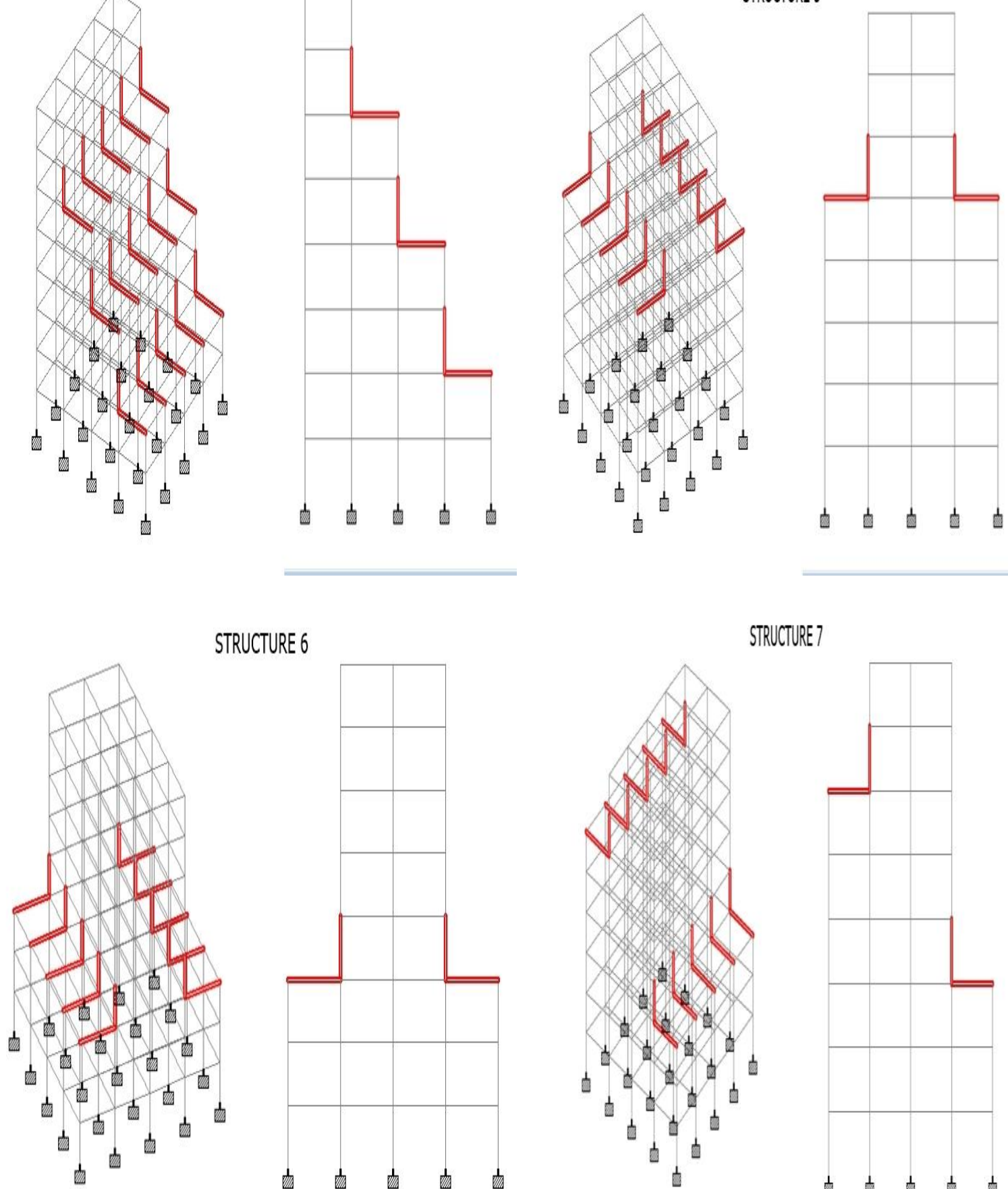

STRUCTURE 6
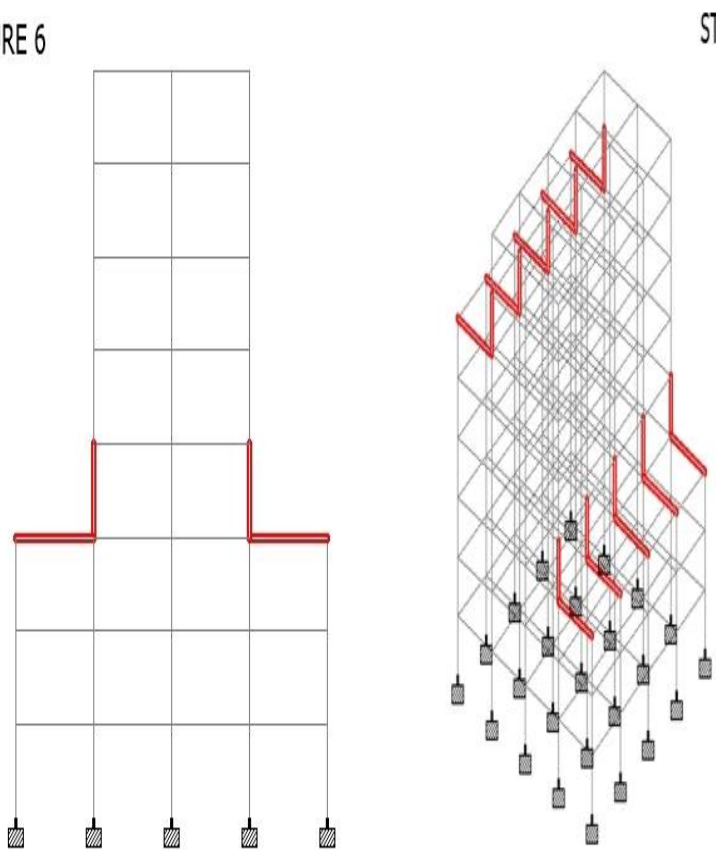

STRUCTURE 7

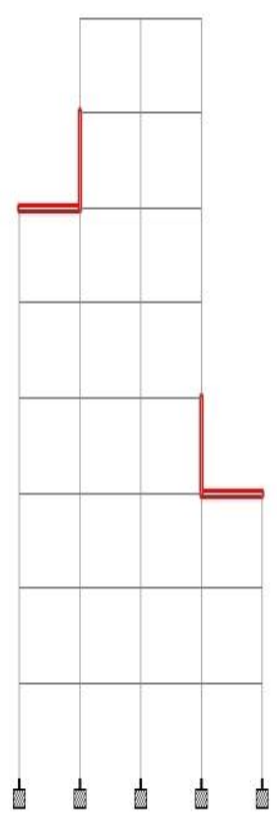

Fig.2: Types Of Structure Used.

Corresponding to zone IV given in IS 1893 (Part 1) : 2002 are considered for design. Type of frame is special moment resisting RC frame with response reduction factor of 5 , type of soil is hard soil and $5 \%$ damping ratio is considered. Dimensions of beams and columns are 400x300 mm and 400x400 mm respectively. All the load combinations are taken from IS 1893 (Part 1):2002. Various seismic parameters are summarized below in the table 1 
Table 1 Seismic Parameters

\begin{tabular}{|c|c|c|}
\hline S.No & Seismic Parameters & Value \\
\hline 1 & Zone factor & 0.24 \\
\hline 2 & Importance factor(I) & 1.5 \\
\hline 3 & Response reduction factor (RF) & 1 \\
\hline 4 & Rock and soil site factor (SS) & 0.05 \\
\hline 5 & Damping ratio & 1 \\
\hline 6 & Type of structure & \\
\hline
\end{tabular}

\section{RESULTS AND DISCUSSION}

The comparison of the frames is done on the basis of axial force, shear force and bending moment. The forces for the middle frame is calculated. Beams and columns of the structure with setbacks are compared with the same beams and columns in regular structure. Graphs were plotted to show how these forces change from regular to irregular structure. The graphs can be seen in Fig.3. As it can be seen from the graphs that the value of axial force in all the cases i.e. for beams and columns is coming out more for structure with setbacks, which means the chances of failure of the structure become more as we introduce irregularities in a structure. The earthquake force induced in a building during earthquake need to be brought down to the base level by the shortest path but the building with setback cause a sudden jump in these forces at the point of discontinuity due to which the value of axial force is coming out to be more in irregular structure. Also it is noted that the value of shear force and bending moment is decreasing as we move from regular to irregular structure which may be due to the reduction in mass of the structure.

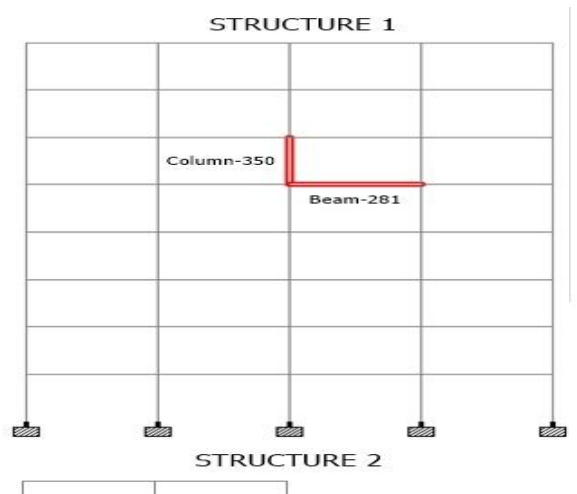

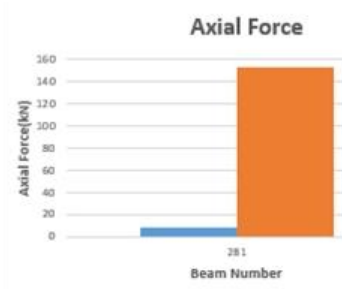

Shear Force

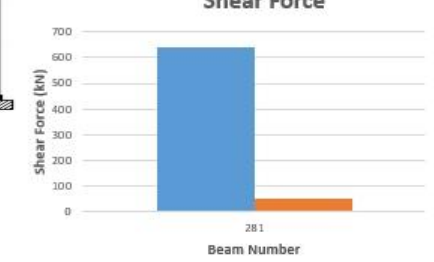

Bending Moment

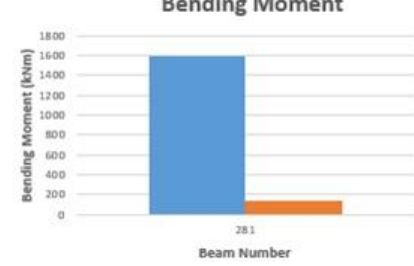

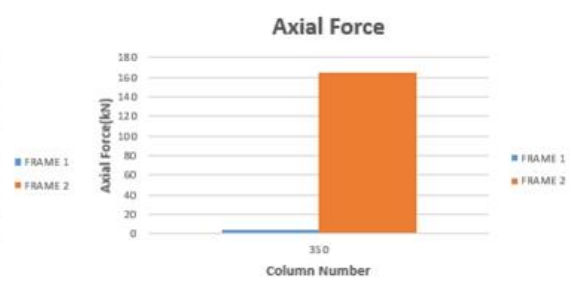

Shear Force

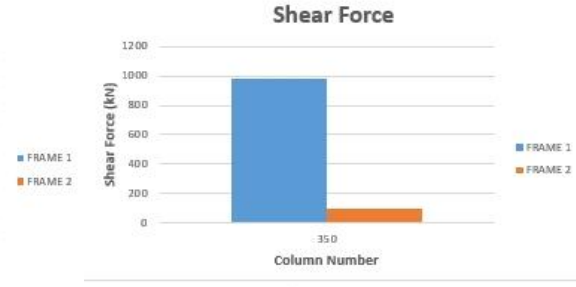

Bending Moment

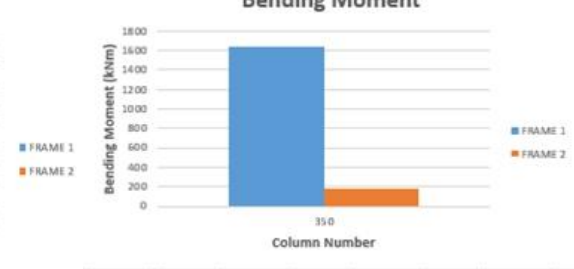



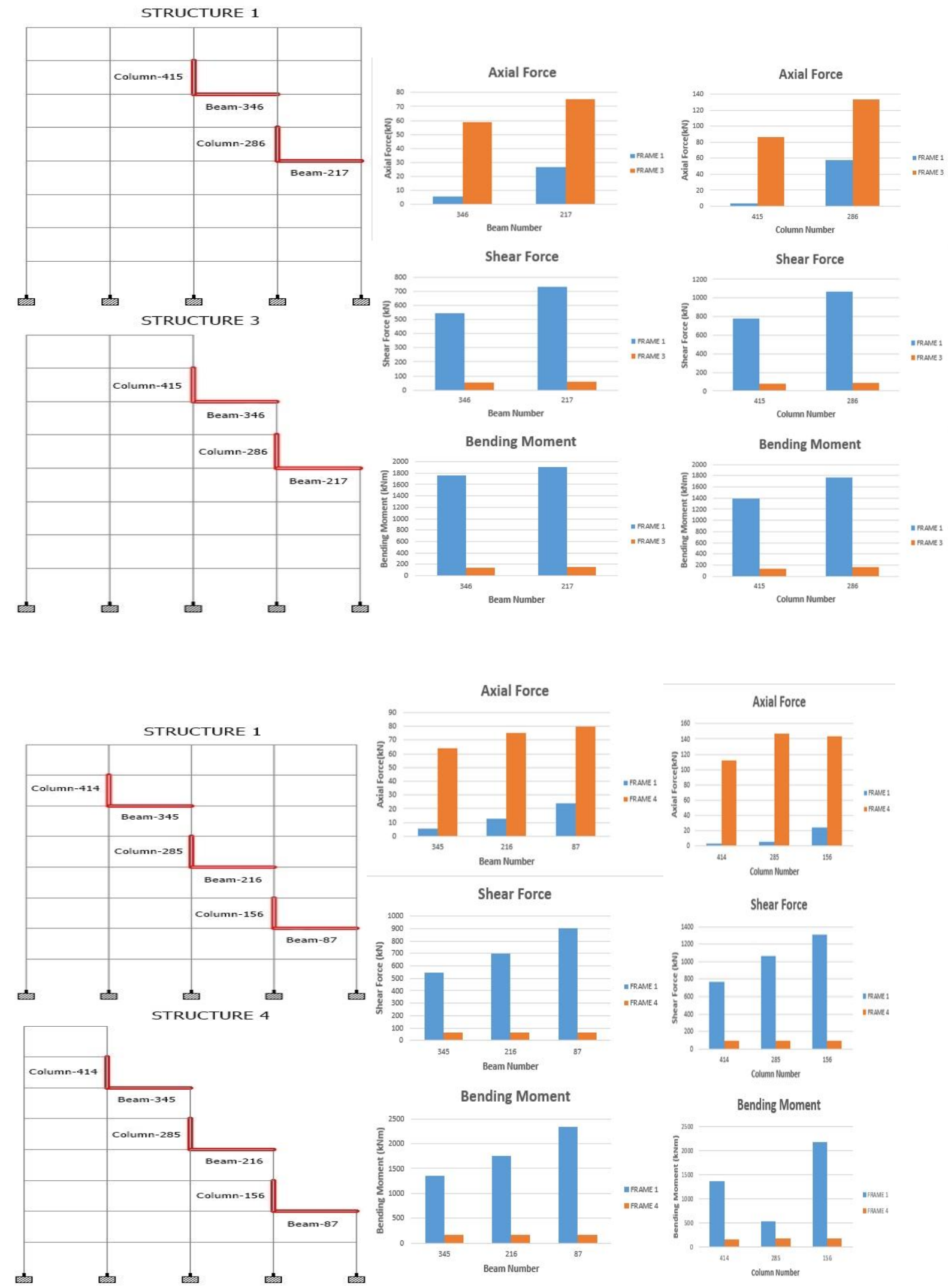
Axial Force
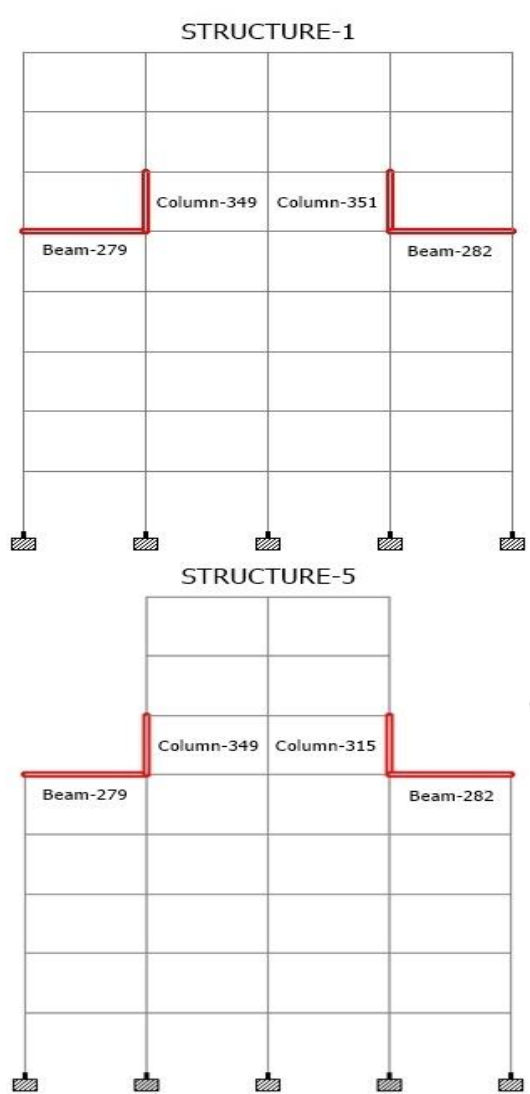

Structure-1
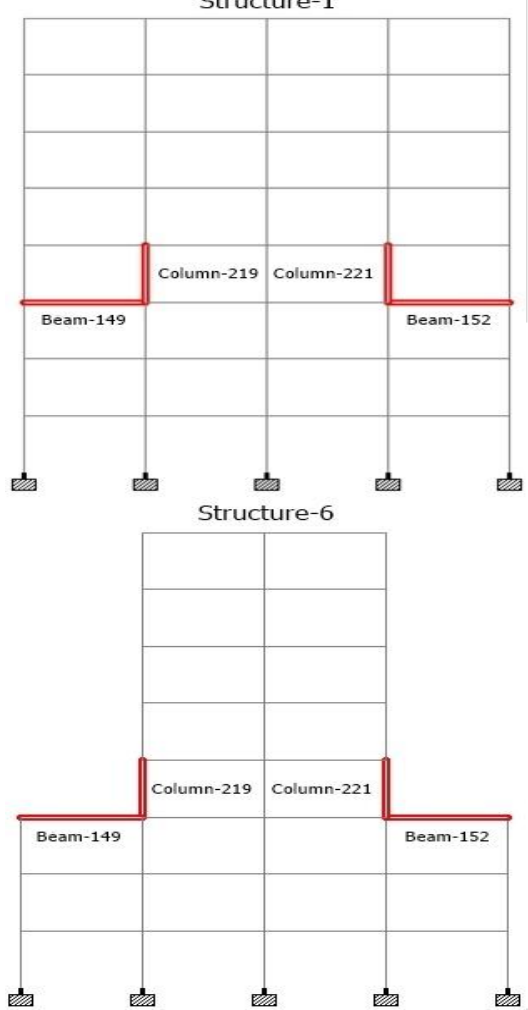

Shear Force
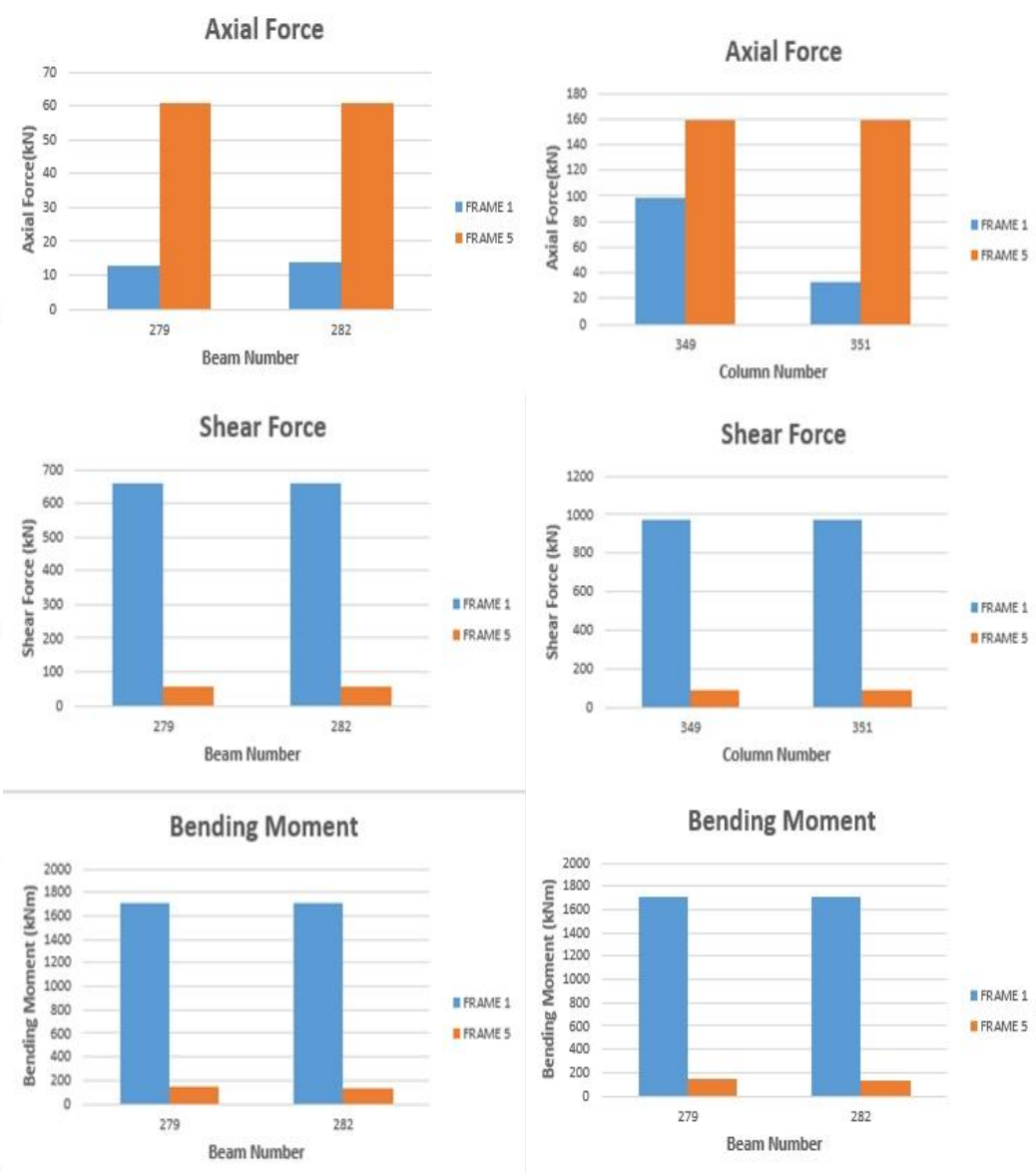

Axial Force
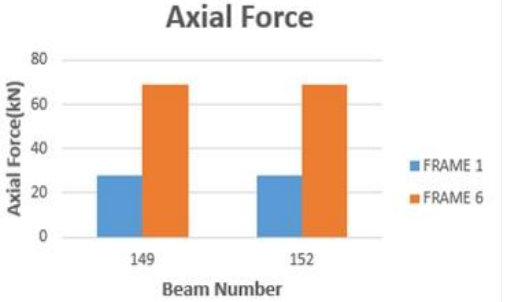

Shear Force

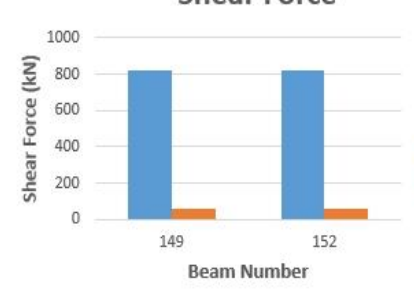

Bending Moment

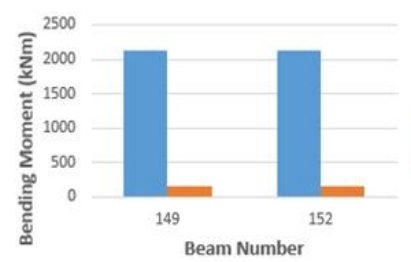

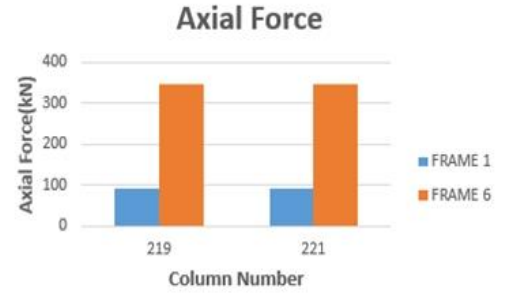

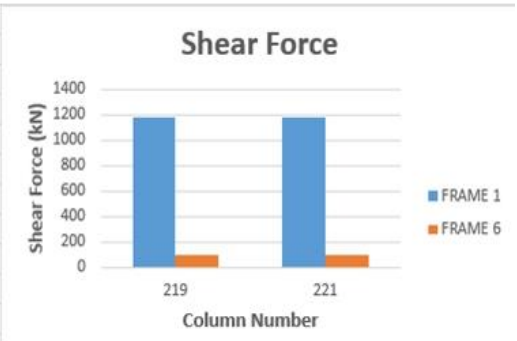

Bending Moment

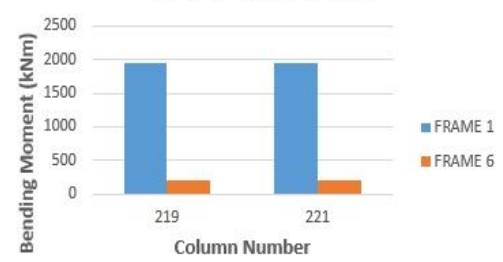




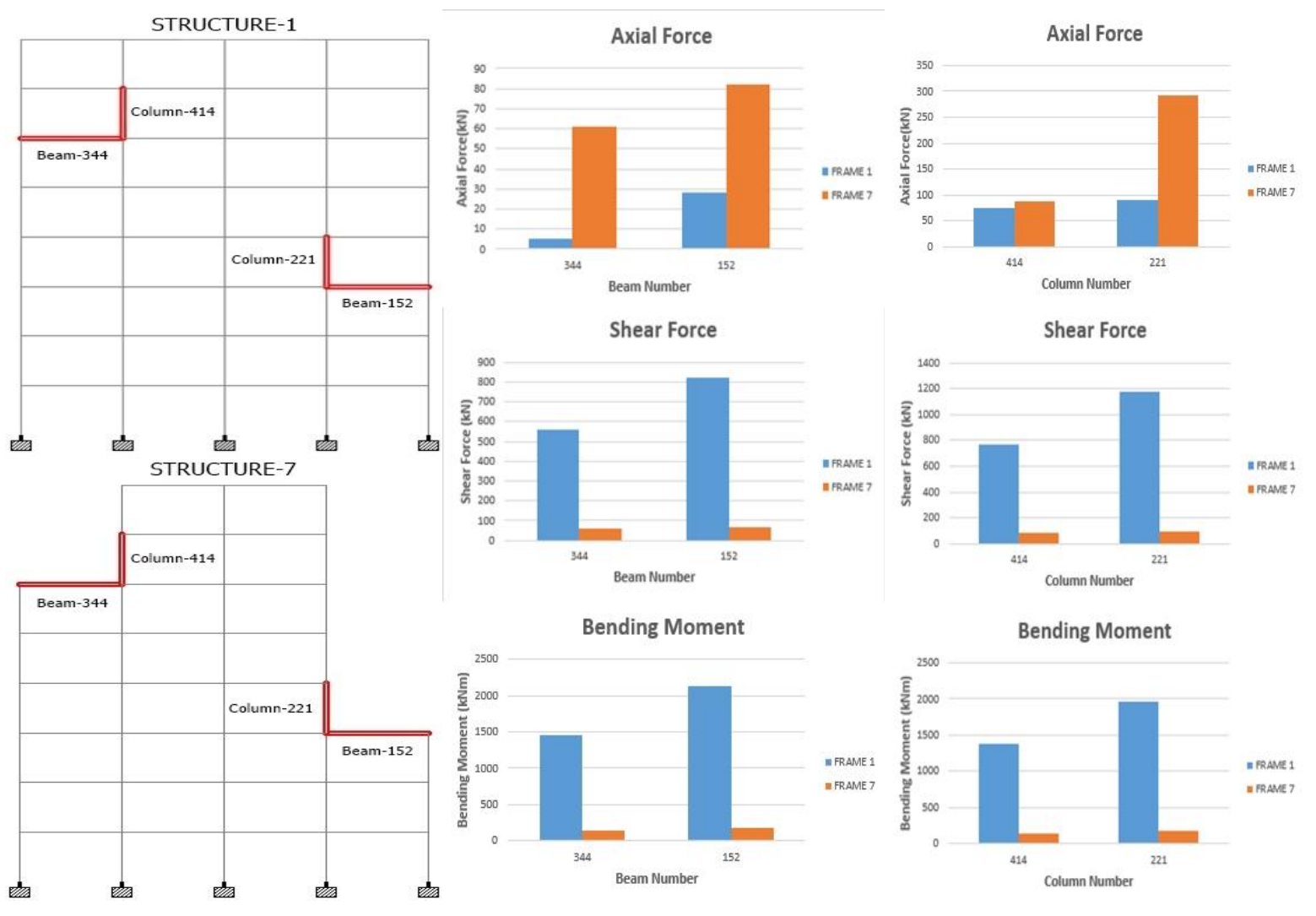

Fig.3 Comparison of Irregular Frames with Regular Frame

\section{CONCLUSION}

The comparison of all structures was done with the structure having setbacks on the basis of axial force, shear force and bending moment. It was seen that the value of axial force is increasing by a very large amount as we move from regular to irregular structure. The value of shear force and bending moment however decreases from regular to irregular structure which is due to the reduction in mass of the structure. From the above discussion it can be concluded that the building with setbacks results in poor performance and the chances of failure of beams and columns in these buildings become more due to increased stresses in columns as well as in beams at setbacks. That is why it is not recommended to introduce setbacks in the structure, if there is some constraint to introduce setbacks in a structure, they should be in permissible limits, and otherwise it is not recommended to introduce irregularities in the structure

\section{REFERENCES}

[1] BIS. "IS 1893 (Part 1)-2002: Indian Standard Criteria for Earthquake Resistant Design of Structures, Part 1 - General Provisions and Buildings (Fifth Revision)", Bureau of Indian Standards, New Delhi

[2] S.Varadharajan, V.K. Sehgal and B.Saini , "Review of different structural irregularities in buildings", Journal of structure engineering 393 Vol. 39, No. 4, October - November 2012 Journal of Structural Engineering Vol. 39, No. 5, December 2012 January 2013 pp. 393-418

[3] Devesh P. Soni and Bharat B. Mistry, "Qualitative review of seismic response of vertically irregular building”, ISET Journal of Earthquake Technology, Technical Note, Vol. 43, No. 4, December 2006, pp. 121-132

[4] Ankesh Sharma \& Biswobhanu Bhadra, (2013), "Seismic analysis and design of vertically irregular RC building frame".

[5] Dileshwar Rana, Prof. Juned Raheem (2015), "Seismic Analysis of Regular \& Vertical Geometric Irregular RCC Framed Building ", International Research Journal of Engineering and Technology (IRJET)

[6] A.A.K. Al-Ali and H. Krawinkler," Effect of Effects of Vertical Irregularities on Seismic Behavior of Building Structures", Retrieved from https://blume.stanford.edu/content/effects-vertical-irregularities-seismic-behavior-building-structures

[7] Vertical irregularities in structures, Retrieved from http://civil-engg-world.blogspot.in/2011/04/vertical-irregularities-instructures.html 